\title{
Rate of perioperative neurological complications after surgery for cervical spinal cord stimulation
}

\author{
Andrew K. Chan, MD, Ethan A. Winkler, MD, PhD, and Line Jacques, MD \\ Department of Neurological Surgery, University of California, San Francisco, California
}

OBJECTIVE Cervical spinal cord stimulation (CSCS) is used to treat pain of the cervical region and upper extremities. Case reports and small series have shown a relatively low risk of complication after CSCS, with only a single reported case of perioperative spinal cord injury in the literature. Catastrophic cSCS-associated spinal cord injury remains a concern as a result of underreporting. To aid in preoperative counseling, it is necessary to establish a minimum rate of spinal cord injury and surgical complication following cSCS.

METHODS The Nationwide Inpatient Sample (NIS) is a stratified sample of $20 \%$ of all patient discharges from nonfederal hospitals in the United States. The authors identified discharges with a primary procedure code for spinal cord stimulation (ICD-9 03.93) associated with a primary diagnosis of cervical pathology from 2002 to 2011. They then analyzed short-term safety outcomes including the presence of spinal cord injury and neurological, medical, and general perioperative complications and compared outcomes using univariate analysis.

RESULTS Between 2002 and 2011, there were 2053 discharges for cSCS. The spinal cord injury rate was $0.5 \%$. The rates of any neurological, medical, and general perioperative complications were $1.1 \%, 1.4 \%$, and $11.7 \%$, respectively. There were no deaths.

CONCLUSIONS In the largest series of cSCS, the risk of spinal cord injury was higher than previously reported $(0.5 \%)$. Nonetheless, this procedure remains relatively safe, and physicians may use these data to corroborate the safety of cSCS in an appropriately selected patient population. This may become a key treatment option in an increasingly opioiddependent, aging population.

http://thejns.org/doi/abs/10.3171/2015.10.SPINE15670

KEY WORDS cervical spinal cord stimulation; SCS; neurostimulation; neuromodulation

$\mathrm{C}$ ERVICAL spinal cord stimulation (CSCS) is an important treatment option in the management of pain in the cervical region and upper extremities. In retrospective and prospective multicenter studies, it has been shown to be efficacious in relieving pain and improving quality of life. , $^{4,10,11,14,18,25,28,31,33,35-37}$ However, comprehensive studies into the safety of cSCS are lacking in the literature.

Complications are taken from case reports and small series and are usually minor and without resultant long-term morbidity. These include hardware malfunction, lead migration, lead fracture, implant site pain, infection, and nontherapeutic stimulation among others. ${ }^{4,7,10,11,14,18,25,28,31,33,35-37}$ Current small patient volume studies limit the detection of rare cSCS related complications and may lead to false safety assurances among implanters, clinicians, and patients.
The most feared complication is perioperative spinal cord injury, and it is rarely reported. In a systematic review, Deer et al. ${ }^{7}$ showed the absence of spinal cord injury in 218 total patients across 11 studies. In our extensive research, we only found a single case report of perioperative spinal cord injuries after cSCS. ${ }^{24}$ In 2007 Meyer et al. reported a case of quadriparesis after cSCS during a closed percutaneous revision for complex regional pain syndrome. A Tuohy needle had been placed at the T-3 interspace resulting in an inadvertent intramedullary placement of an electrode, with the distal tip at the level of C-2. There is report of significant injury in noncervical spinal cord stimulation, ${ }^{1-3,6,12,13,15,22,29,32}$ but a paucity of literature studying such injuries in the cervical population.

Investigation of the safety of cSCS- outside of the confines of small series and case reports-will ensure more

ABBREVIATIONS CSCS $=$ cervical spinal cord stimulation; DVT $=$ deep venous thrombosis; HCUP $=$ Healthcare Cost and Utilization Project; ICD-9 $=$ International Classification of Diseases, Ninth Revision; LOS = length of stay; NIS = Nationwide Inpatient Sample; PE = pulmonary embolism.

SUBMITTED June 6, 2015. ACCEPTED October 21, 2015.

INCLUDE WHEN CITING Published online March 4, 2016; DOI: 10.3171/2015.10.SPINE15670. 
informed decision-making when pursuing cSCS as an option for cervical and upper limb pathology. We examined the Nationwide Inpatient Sample (NIS) from 2002 through 2011 to assess the rate of perioperative neurological complications associated with cSCS.

\section{Methods}

The NIS was developed as part of the Healthcare Cost and Utilization Project (HCUP) from the Agency for Healthcare Research and Quality (AHRQ). It is the largest publicly available inpatient hospital database that catalogs discharge data from a stratified sample of approximately $20 \%$ of all nonfederal hospitals in the US. For this study, we obtained the NIS data for the 10-year period 20022011. Because the NIS is drawn from a sample that includes all patients discharged from sampled hospitals, the data can be used to estimate total annual complications among other variables for all nonfederal hospitals in the US. The dataset presented in this study is thus extrapolated using the weighting variables provided by HCUP.

\section{Patient Population}

International Classification of Diseases, Ninth Revision (ICD-9) codes were used to identify discharges with a primary procedure code of implantation or replacement of spinal neurostimulator lead(s) (03.93). Discharges with a primary diagnosis code of cervical pathology were then identified: neck pain (723.1), cervicocranial syndrome (723.2), cervicobrachial syndrome (723.3), brachial neuritis/radiculitis (723.4), other disorders of cervical region (723.8), postlaminectomy syndrome/failed-neck surgery syndrome (722.81), reflex sympathetic dystrophy/complex regional pain of the upper limb (337.21), cervical root lesions (353.2), brachial plexus lesions (353.0), shoulder pain (719.41, 719.51, 719.61, 719.81, 719.91), and upper limb pain $(719.42,719.43,719.44,719.52-0.54,719.62-0.64$, 719.82-0.84, 719.92-0.94).

\section{Patient Characteristics}

Age, sex, race, income quartile of the patient's zip code, and payer status were coded within the database. Medical comorbidities were defined using a modified version of the Elixhauser comorbidity score,$^{8}$ which excluded the 2 neurological comorbidity variables, "other neurological deficit" and "paralysis" such that the highest possible comorbidity score was 28 . Comorbidities of the cervical spine were also identified using ICD-9 codes: ankylosing spondylitis (720.0); cervical spondylosis without myelopathy (721.0); cervical spondylosis with myelopathy (721.1); spinal stenosis in the cervical region (723.0); ossification of the posterior longitudinal ligament (723.7); other/unspecified cervical pathology $(723.8-0.9,722.91)$; displacement of a cervical disc without myelopathy (722.0); cervical disc degeneration (722.4); intervertebral disc disorder with myelopathy, cervical region (722.71); and myelopathy $(336.3,336.8,336.9)$. Payer status was defined by combining the primary and secondary payer variables and placing discharges into the exclusive categories: "private insurance," "Medicaid without private insurance," "Medicare with neither private insurance nor Medicaid," and "other."

\section{Hospital Characteristics}

The NIS provides data on hospital size (small, medium, large), location (urban or rural), teaching hospital status, and region (Northeast, Midwest, South, West), as well as annual hospital caseload for a specific procedure by discharge number. Hospital caseload was calculated by annual number of discharge records containing any procedure code of 03.93 with a concomitant primary diagnosis code indicating cervical or upper limb pathology.

\section{Complications/Outcomes Definitions}

We identified a number of potential complications resulting from cSCS. The complications included in our analysis and their respective ICD-9 codes are listed in Table 1. As the information within the NIS is based on discharge-level patient information, complications reported are those that occur during the course of in-patient hospitalization.

We examined secondary, short-term safety outcomes provided in the dataset including length of stay (LOS), discharge status, and mortality. Discharges that were to home or home health care were labeled as "routine." Discharges to short-term hospital or skilled nursing facility, or death were referred to as "nonroutine" discharge.

\section{Statistical Analysis}

Statistical analyses were performed using built-in and custom scripts (Matlab, Mathworks). The Wilcoxon ranksum test or a chi-square, with Yates' correction for continuity for tests utilizing 1 degree of freedom, was used. A hierarchical, logistic regression model (SAS procedure GLIMMIX, SAS Institute) was used to analyze variables that predicted the presence of complications. Predictor variables included age, sex, modified comorbidity score, race, income quartile of patient zip code, payer status, hospital experience, size (number of patient beds), region, setting (urban or rural), teaching status, and year of discharge. The unique hospital identification code served as the nesting variable. We accounted for missing data with single imputation based on deterministic regression modeling in an $\mathrm{R}$ environment ( $\mathrm{R}$ Development Core Team). Multinomial logistic, binomial logistic, and linear regression models were used as appropriate, and a $\mathrm{p}<0.05$ was considered statistically significant. Bonferroni Correction for multiple comparisons was used where appropriate. Results are reported \pm standard error of the mean or as a frequency with percentage. Frequency, where presented, is rounded to the nearest whole number patient after application of the HCUP dataset weighting variable.

\section{Results \\ Patient Characteristics}

From January 1, 2002, through 2011, there were 425 discharge records for cSCS; this suggests that the actual number of discharges for cSCS from nonfederal hospitals is an estimated 2053. Table 2 shows the characteristics of patients who underwent cSCS.

The average age of discharged patients was $46.0 \pm 0.6$ years, and $67.0 \%$ were female. The mean modified co- 
TABLE 1. Complications by type and ICD-9 code

\begin{tabular}{|c|c|}
\hline Complication & ICD-9 Code \\
\hline Nervous system complications & $997.00-997.09$ \\
\hline Spinal cord injury & $952.00-952.09$ \\
\hline Hemiplegia or hemiparesis & $342.00-342.92$ \\
\hline Nerve root/brachial plexus injury & $953.0,953.4$ \\
\hline Sympathetic nerve injury & 954.0 \\
\hline Head \& neck artery injury & $900.00-900.03,900.82,900.89,900.9$ \\
\hline Hematoma or hemorrhage complicating a procedure & $998.11,998.12,997.02$ \\
\hline Seroma complicating a procedure & 998.13 \\
\hline Mechanical complications & $996.2,996.59,998.2$ \\
\hline Accidental puncture or laceration & 998.2 \\
\hline Infectious complications, related to a mechanical device & $996.60,996.63$ \\
\hline Infectious complications, postoperative & $995.4,998.51-998.59$ \\
\hline Perioperative shock & $998.00-998.09$ \\
\hline CSF rhinorrhea (CSF leak) & 349.81 \\
\hline Dural tear & $349.31-349.39$ \\
\hline Persistent postoperative fistula & 998.6 \\
\hline Wound complication & $998.30-998.32,998.83$ \\
\hline Retained foreign body & $998.4,998.7$ \\
\hline DVT/PE & $\begin{array}{l}\text { 415.11-415.19,451.11, 451.19, 451.81, } \\
\quad 453.40-453.42,995.4\end{array}$ \\
\hline Urinary tract infection & 599.0 \\
\hline Pneumonia & 486, 997.31-997.32 \\
\hline \multicolumn{2}{|l|}{ Other implant-related complications* } \\
\hline Other complications due to a nervous system device, implant, graft & 996.75 \\
\hline Unspecified or other nervous system complication & $997.00,997.01,997.09$ \\
\hline Complications affecting other specified body systems, not elsewhere classified, hypertension & 997.91 \\
\hline Complications affecting other specified body systems, not elsewhere classified & 997.99 \\
\hline Other \& unspecified complications of medical care, not elsewhere classified & 999.9 \\
\hline Late effect of complications of surgical \& medical care & 909.3 \\
\hline Other specified complications of procedures not elsewhere classified & 998.89 \\
\hline Unspecified complication of procedure, not elsewhere classified & 998.9 \\
\hline Nervous system complications from surgically implanted device & 349.1 \\
\hline
\end{tabular}

* The variable "other implant-related complications" was coded as a single variable utilizing all of the subsequent ICD- 9 codes.

morbidity score was $1.0 \pm 0.1$. With regard to institutional characteristics, hospitals discharging patients with cSCS had an average annual caseload of 2.6 \pm 0.1 surgeries for cSCS per year. A majority of procedures were performed at large (68.9\%) urban (96.8\%) teaching hospitals (60.4\%). The average LOS was $2.4 \pm 0.1$ days. The largest percentage of discharges, $96.8 \%$, were coded as discharged to either home or home health care (routine). Of those discharged "nonroutinely," $2.7 \%$ were transferred to a skilled nursing facility or other long-term care facility, $5.1 \%$ were discharged with home health care, and $0.3 \%$ were transferred to another hospital.

\section{Complications}

Of the patients discharged, $11.7 \%$ developed complications during hospitalization, including $0.5 \%$ who sustained a spinal cord injury, while $1.1 \%$ developed neurological complications of some type, and $1.4 \%$ developed a medical complication. The complications indicated by ICD-9 codes included the following: 1) mechanical complications (5.8\%); 2) implant-related complications (2.4\%); $3)$ nervous system complications $(0.9 \%)$; 4 ) urinary tract infection $(0.7 \%)$; 5) spinal cord injury $(0.5 \%)$; 6) hematoma, hemorrhage, or seroma $(0.5 \%) ; 7)$ pneumonia $(0.5 \%)$; 8 ) infectious complications of a mechanical device ( $0.3 \%)$; 9 ) infectious complications postoperative $(0.3 \%)$; 10$)$ accidental laceration or puncture $(0.2 \%)$; 11$)$ DVT/PE $(0.2 \%)$.

No patients died during hospitalization. Table 3 shows the complications associated with cSCS.

Of the discharges associated with a complication, 34.7\% were associated with reoperation during the index hospitalization. Eleven patients returned to the operating room for "removal of spinal neurostimulator lead(s)" (ICD-9 03.94). These were associated with nervous system $(n=4)$ or other complications $(n=7)$. Six patients returned to the operating room for procedures associated with nervous system 
TABLE 2. Characteristics of discharges for cervical spinal cord stimulation

\begin{tabular}{|c|c|}
\hline Characteristic & Value $(\%)^{*}$ \\
\hline Total no. of discharges during period & 2053 \\
\hline Mean age \pm SEM & $46.0 \pm 0.6$ \\
\hline Female & $1376(67.0)$ \\
\hline Mean modified comorbidity score \pm SEM & $1.0 \pm 0.1$ \\
\hline \multicolumn{2}{|l|}{ Race } \\
\hline White & $1653(80.5)$ \\
\hline Black & $184(8.9)$ \\
\hline Hispanic & $142(6.9)$ \\
\hline Asian/Pacific Islander & $21(1.0)$ \\
\hline Native American & $4(0.2)$ \\
\hline Other & $49(2.4)$ \\
\hline \multicolumn{2}{|l|}{ Patient residential zip codes in } \\
\hline 1st income quartile (lowest) & $328(16.0)$ \\
\hline 2nd income quartile & $498(24.3)$ \\
\hline 3rd income quartile & $537(26.2)$ \\
\hline 4th income quartile (highest) & $690(33.6)$ \\
\hline \multicolumn{2}{|l|}{ Type of insurance } \\
\hline Private insurance & $1086(52.9)$ \\
\hline Medicaid w/o private insurance & $127(6.2)$ \\
\hline Medicare w/ neither private insurance nor Medicaid & $300(14.6)$ \\
\hline Neither Medicare, Medicaid, nor private insurance & $540(26.3)$ \\
\hline Mean yearly caseload of procedure hospital ( \pm SEM) & $2.6 \pm 0.1$ \\
\hline Teaching hospital & $1240(60.4)$ \\
\hline Urban hospital & $1987(96.8)$ \\
\hline \multicolumn{2}{|l|}{ Hospital size } \\
\hline Small hospital & $248(12.1)$ \\
\hline Medium hospital & $390(19.0)$ \\
\hline Large hospital & $1415(68.9)$ \\
\hline \multicolumn{2}{|l|}{ Location of hospital } \\
\hline Northeast region & $563(27.4)$ \\
\hline Midwest region & $327(15.9)$ \\
\hline South region & $748(36.4)$ \\
\hline West region & $415(20.2)$ \\
\hline Mean LOS ( \pm SEM) & $2.4 \pm 0.1$ \\
\hline \multicolumn{2}{|l|}{ Discharge status } \\
\hline Routine discharge & $1987(96.8)$ \\
\hline Short-term hospital transfer & $6(0.3)$ \\
\hline Other transfer (includes skilled nursing facility) & $55(2.7)$ \\
\hline Home health care & $105(5.1)$ \\
\hline Against medical advice & $4(0.2)$ \\
\hline Died & $0(0)$ \\
\hline Alive, destination unknown & $0(0)$ \\
\hline
\end{tabular}

LOS = length of stay.

* Because the NIS is drawn from a sample that includes all patients discharged from sampled hospitals, the sample can be used to estimate total annual data for all nonfederal hospitals in the US. The data set presented here is extrapolated using the weighting variables provided by HCUP. Unless otherwise indicated, values represent number of patients (\%). Counts are rounded to the nearest whole number patient after application of the HCUP data set weighting variable.
TABLE 3. Complications of cervical spinal cord stimulation*

\begin{tabular}{|c|c|}
\hline Complication & Value (\%) \\
\hline Any complication $†$ & $240(11.7)$ \\
\hline Mortality rate & $0(0)$ \\
\hline Nervous system complications & $18(0.9)$ \\
\hline Spinal cord injury & $10(0.5)$ \\
\hline Hemiplegia or hemiparesis & $0(0)$ \\
\hline Nerve root/brachial plexus injury & $0(0)$ \\
\hline Sympathetic nerve injury & $0(0)$ \\
\hline Head \& neck artery injury & $0(0)$ \\
\hline Hematoma or hemorrhage complicating a procedure & $10(0.5)$ \\
\hline Seroma complicating a procedure & $0(0)$ \\
\hline Mechanical complications & $119(5.8)$ \\
\hline Accidental puncture or laceration & $4(0.2)$ \\
\hline Infectious complications, related to a mechanical device & $6(0.3)$ \\
\hline Infectious complications, postoperative & $6(0.3)$ \\
\hline Perioperative shock & $0(0)$ \\
\hline CSF rhinorrhea (CSF leak) & $0(0)$ \\
\hline Dural tear & $0(0)$ \\
\hline Persistent postoperative fistula & $0(0)$ \\
\hline Wound complication & $0(0)$ \\
\hline Retained foreign body & $0(0)$ \\
\hline DVT/PE & $4(0.2)$ \\
\hline Urinary tract infection & $14(0.7)$ \\
\hline Pneumonia & $10(0.5)$ \\
\hline Other implant-related complications & $49(2.4)$ \\
\hline Any neurological complication $\ddagger$ & $23(1.1)$ \\
\hline Any medical complication§ & $29(1.4)$ \\
\hline
\end{tabular}

* Counts are rounded to the nearest whole number patient after application of the HCUP data set weighting variable.

$\dagger$ Includes the percentage of discharges with the presence of any of the complications listed in Table 1.

$\ddagger$ Includes the percentage of discharges with the presence of any nervous system complication, spinal cord injury, hemiplegia or hemiparesis, or nerve root/brachial plexus injury.

$\S$ Includes the percentage of discharges with the presence of a deep venous thrombosis/pulmonary embolism, urinary tract infection, or pneumonia.

complications $(n=4)$ and other complications $(n=2)$ not related to lead removal (ICD-9 03.01, 03.02, 03.09, 03.99).

Hierarchical logistic regression analysis did not find a significant predictor of complications in models for the presence of neurological complications, medical complications, spinal cord injury, or any complication.

\section{Differences Between Discharges With and Without Complications}

Table 4 shows the differences between discharges with and without complications. Comparing the patients discharged without complications versus the cohort with complications, the patients with complications had a higher number of males $(\mathrm{p}<0.001)$, more often used Medicare $(\mathrm{p}<0.001)$, and were from lower income zip codes $(\mathrm{p}<$ 0.001 ). Table 5 shows the cervical spinal comorbidities as- 
TABLE 4. Characteristics of patients discharged after cSCS

\begin{tabular}{|c|c|c|c|}
\hline Variable & No Complications (\%) & Any Complication (\%) & p Value \\
\hline Total no. of discharges during period & 1812 & 241 & \\
\hline Mean age \pm SEM $^{*}$ & $45.9 \pm 0.6$ & $46.8 \pm 1.5$ & 0.15 \\
\hline Female & $1,238(68.3)$ & $138(57.2)$ & $<0.001$ \\
\hline Mean modified comorbidity score \pm SEM & $1.0 \pm 0.1$ & $0.9 \pm 0.2$ & 0.54 \\
\hline \multicolumn{4}{|l|}{ Race } \\
\hline White & $1440(79.5)$ & $213(88.4)$ & 0.02 \\
\hline Black & $170(9.4)$ & $13(5.3)$ & \\
\hline Hispanic & $126(7.0)$ & $15(6.4)$ & \\
\hline Asian/Pacific Islander & $20(1.1)$ & $0(0.0)$ & \\
\hline Native American & $5(0.3)$ & $0(0.0)$ & \\
\hline Other & $51(2.8)$ & $0(0.0)$ & \\
\hline \multicolumn{4}{|l|}{ Patient residential zip codes in } \\
\hline 1st income quartile (lowest) ${ }^{*}$ & $281(15.5)$ & $47(19.6)$ & $<0.001$ \\
\hline 2nd income quartile* & $422(23.3)$ & $76(31.4)$ & \\
\hline 3rd income quartile* & $495(27.3)$ & $42(17.6)$ & \\
\hline 4th income quartile (highest) ${ }^{*}$ & $614(33.9)$ & $76(31.4)$ & \\
\hline \multicolumn{4}{|l|}{ Type of insurance } \\
\hline Private insurance* & $989(54.6)$ & $97(40.2)$ & $<0.001$ \\
\hline Medicaid w/o private insurance* & $118(6.5)$ & $10(4.0)$ & \\
\hline Medicare w/ neither private insurance nor Medicaid* & $236(13.0)$ & $64(26.6)$ & \\
\hline Neither Medicare, Medicaid, nor private insurance* & $469(25.9)$ & $70(29.2)$ & \\
\hline Mean yearly caseload of procedure hospital \pm SEM & $2.7 \pm 0.1$ & $2.1 \pm 0.3$ & 0.05 \\
\hline Teaching hospital $^{*}$ & $1133(62.5)$ & $107(44.5)$ & $<0.001$ \\
\hline Urban hospital* $^{*}$ & $1769(97.6)$ & $219(90.8)$ & $<0.001$ \\
\hline \multicolumn{4}{|l|}{ Hospital size } \\
\hline Small hospital & $216(11.9)$ & $33(13.6)$ & 0.08 \\
\hline Medium hospital & $333(18.4)$ & $57(23.5)$ & \\
\hline Large hospital & $1263(69.7)$ & $151(62.9)$ & \\
\hline \multicolumn{4}{|l|}{ Location of hospital } \\
\hline Northeast region & $497(27.4)$ & $65(26.9)$ & 0.44 \\
\hline Midwest region & $295(16.3)$ & $31(13.0)$ & \\
\hline South region & $652(36.0)$ & $97(40.1)$ & \\
\hline West region & $368(20.3)$ & $48(20.0)$ & \\
\hline Mean LOS \pm SEM & $2.2 \pm 0.1$ & $3.8 \pm 0.4$ & 0.24 \\
\hline \multicolumn{4}{|l|}{ Discharge status } \\
\hline Routine discharge* & $1773(97.8)$ & $215(89.2)$ & $<0.001$ \\
\hline Short-term hospital transfer* & $0(0)$ & $5(2.2)$ & \\
\hline Other transfer (includes skilled nursing facility)* & $34(1.9)$ & $21(8.6)$ & \\
\hline Home health care* & $74(4.1)$ & $30(12.6)$ & \\
\hline Against medical advice* & $5(0.3)$ & $0(0)$ & \\
\hline Died* $^{*}$ & $0(0)$ & $0(0)$ & \\
\hline Alive, destination unknown* & $0(0)$ & $0(0)$ & \\
\hline
\end{tabular}

* Statistically significant association was determined using Bonferroni correction (alpha 0.05/13 comparisons equals a correct alpha of alpha 0.0038). Counts are rounded to the nearest whole number patient after application of the HCUP data set weighting variable.

sociated with discharges with and without complications. Of note, there was a greater percentage of patients with cervical spondylotic myelopathy and cervical spinal stenosis in the cohort with complications ( $p<0.001$ for both comparisons). The cohort with complications more often received their surgeries at nonteaching hospitals in nonurban locations ( $p<0.001$ for both comparisons). Complications were associated with a greater number of discharges other than to home or home health care $(\mathrm{p}<0.001)$. Of note, age, medical comorbidity, spinal comorbidity, and 
TABLE 5. Comorbidities associated with cervical spinal cord stimulation

\begin{tabular}{|c|c|c|c|}
\hline Comorbidity & No Complications (\%) & Any Complication (\%) & $p$ Value \\
\hline Any cervical spine comorbidity & $228(12.6)$ & $20(8.3)$ & 0.05 \\
\hline Cervical spondylosis w/o myelopathy & $29(1.6)$ & $5(2.2)$ & 0.59 \\
\hline Cervical spondylosis w/ myelopathy* & $5(0.3)$ & $5(2.1)$ & $<0.001$ \\
\hline Cervical spinal stenosis* & $5(0.3)$ & $5(2.2)$ & $<0.001$ \\
\hline Other/unspecified ${ }^{*} \dagger$ & $172(9.5)$ & $5(1.9)$ & $<0.001$ \\
\hline Displacement of cervical disc w/o myelopathy & $11(0.6)$ & $0(0)$ & \\
\hline Cervical disc degeneration & $9(0.5)$ & $0(0)$ & \\
\hline Intervertebral disc disorder w/ myelopathy, cervical region & $0(0)$ & $0(0)$ & \\
\hline Myelopathy & $0(0)$ & $0(0)$ & \\
\hline
\end{tabular}

yearly cSCS caseload did not have a significant impact on the complication rate.

\section{Discussion}

Our study is the largest study reporting short-term complications after cSCS in a multicenter, nonselected hospital setting. Our results reveal that cSCS is associated with higher than previously reported rates of perioperative neurological complications and spinal cord injury $(1.1 \%$ and $0.5 \%$, respectively). Patients who developed complications more often had cervical spondylotic myelopathy and cervical spinal stenosis; were more often discharged from nonteaching hospitals; and were less likely to be discharged to home or home health care.

Age, medical comorbidity, and hospital caseload did not differ in patients with and without perioperative complications.

As compared with non-cervical-specific SCS, the present study's neurological complication rate is 2 -fold higher than the immediate postoperative complication rate of other large database studies. In a study of 395 patients undergoing non-cervical-specific SCS lead implantations, an immediate index hospitalization neurological complication rate of $0.51 \%$ was reported. ${ }^{1}$ In another study using the FDA Manufacturer and User Facility Device Experience database, Levy and colleagues reported that $239(0.54 \%)$ of a total 44,587 electrode implantation procedures were associated with a neurological complication. ${ }^{22}$ This confirms that the rate of neurological and spinal cord injury after cSCS is greater than previously reported in the noncervical-specific SCS population. These findings should serve as a precaution in future discussions with the patient regarding surgical risk and should increase the surgeon's vigilance regarding the treatment planning process. It is important to note, that the present rate of neurological injury refers only the immediate postoperative period. Rates of neurological injury due to cSCS will be even higher with known long-term neurological complications of cSCS including remote spinal cord injury from stimulator mass effect, ${ }^{9}$ local tissue reaction causing cord injury, ${ }^{5,16,21,30,34}$ and lead migration. ${ }^{1}$
Aside from direct cord injury, and epidural hematoma, associated neurological deficits remain a concern after cSCS and are described in case reports. Published rates of epidural hematoma in a large, non-cervical-specific SCS study reveal epidural hematoma as a complication of $0.19 \%$ of surgeries. ${ }^{22}$ Our study reveals the hematoma rate alone for cSCS to be similar (0.22\%). If the rate of hematoma is summed to the rate of postoperative hemorrhage, the rate of vascular complications is $0.5 \%$. Anatomically, this may be due to a relative increase in size of the epidural space in the remainder of the spine relative to the cervical spine (lumbar 5-6 mm, cervical 1-2 $\mathrm{mm}$ ) and smaller cervical spinal canal size. Further study into the anatomical and physiological basis of increased hematoma and hemorrhage formation after cSCS relative to SCS should be undertaken.

To avoid neurological complications and spinal cord injury, it may be useful to evaluate spinal imaging prior to cSCS. Patients undergoing cSCS often have medically refractory cervical and upper extremity pain that may be associated with structural cervical degenerative disease. In the present study, the cohort of cSCS associated with complications included a 7-fold greater number of patients who were reported to have cervical spondylotic myelopathy and cervical spinal stenosis at baseline. This suggests that patient selection via measurements of spinal canal size and baseline determination of spinal cord deformation from bony or discal abnormality-as Levy and colleagues $^{22}$ proposed in their paper "Expert opinion recommendation for safe SCS surgery" - may have a role in selecting the optimal surgical candidate. This bears some significance, as complications in our study were associated with worse short-term outcomes including nonroutine discharge disposition (not to home or home health care) and a trend toward increased LOS. Of note, age, medical comorbidity, and hospital caseload were not factors that were associated with complications. As has been suggested for deep brain stimulation, ${ }^{23}$ this may be partially due to the low baseline rate of surgical complications or overall low caseload practice of surgeons offering cSCS. Further study is necessary to elucidate a relationship between these factors and complications related to cSCS. 
Our overall complication rate, including medical complications, is 2-fold higher than that reported in a previous large study for SCS for failed back surgery syndrome, in which leads were placed in the thoracic spine. In a retrospective, multicenter, Medicare claim-based database study of 395 cases who underwent either percutaneous or paddle lead SCS implantation, $5.1 \%$ of patients had some index hospitalization complication ${ }^{20}$ as compared with $11.7 \%$ in our study. This discrepancy may in part be due to differing anatomy of the thoracic and cervical spine or a more comprehensive capturing of postoperative complications in our study. To this point, our perioperative rate for individual complications such as DVT/PE (0.2\%) and pneumonia $(0.5 \%)$ is similar to that seen in the work of Lad and colleagues $\left(0.3 \%\right.$ and $0.8 \%$, respectively) ${ }^{20}$ In contrast, our rate of infection $(0.6 \%)$ and wound complication $(0 \%)$ differs from the aforementioned study $(0 \%$ and $1.3 \%$, respectively). ${ }^{20}$ Nonetheless, as is true for SCS, cervical SCS remains relatively safe in the perioperative period with respect to medical and general postsurgical complications.

In summary, our study demonstrates that cSCS is considered safe, with perioperative spinal cord injury and neurological insult occurring rates of $0.5 \%$ and $1.1 \%$, respectively. It has been shown to be efficacious ${ }^{4,7}$, $10,11,14,18,25,28,31,33,35-37$ and long-term complication rates are acceptable for surgery in the appropriate patient. In a systematic review of $180 \mathrm{cSCS}$ patients across 10 studies with up to 88 months of follow-up after cSCS, the rate of hardware malfunction (17.8\%), lead migration (13.9\%), lead fracture $(6.7 \%)$, pain over implant site $(4.4 \%)$, infection $(2.2 \%)$, over- or understimulation $(1.1 \%)$, intermittent stimulation $(0.5 \%)$, and other complications $(8.3 \%)$ with the absence of any neurological injury supports a low long-term risk of cSCS. ${ }^{6}$ Studies that have evaluated non-cervicalspecific SCS have also supported its cost-effectiveness in treating pain. ${ }^{17}$ Lumbar SCS for chronic pain after failed back surgery syndrome has been associated with improved outcomes ${ }^{1,27}$ and decreased complications - without an increase in $\operatorname{cost}^{26}$-relative to lumbar reoperation. ${ }^{20}$ The extent to which these data apply to cSCS should be explored in future studies. Appropriate utilization of cSCS may be key in the treatment of cervical and upper-extremity pain in an increasingly opioid dependent, aging population.

We acknowledge certain limitations of this study. First, the NIS is a retrospective dataset with associated limitations. Second, the NIS complication data are an administrative dataset limited by ICD-9 coding. As a code intended for billing purposes, this scheme may fall short of providing a full clinical picture of the perioperative cSCS patient and the specific nature of a coded complication, such as would be provided with a prospective study. Indeed, as application of ICD-9 codes to hospital discharges is undertaken by individuals, there may be inconsistency in the complication data. Although we conducted an exhaustive search in ICD-9 coding to capture the full breadth of perioperative complications in our dataset, shortcomings and inconsistencies in coding will limit the ability to capture all potential complications from cSCS. For example, we do not cover long-term complications or outcomes (e.g., lead migrations, fractures, revisions/reoperations, local tissue reaction, stimulation effect failure, pain reduc- tion, and quality of life improvement) of cSCS, which are beyond the scope of the present study. We believe that our complication rates represent a robust minimum periprocedural complication rate for cSCS. Lastly, it remains unknown which method of lead implantation-percutaneous versus paddle leads or anterograde versus retrograde lead placement-was undertaken for each cSCS implantation. The method of electrode implantation, surgeon familiarity with degenerative or complicated anatomy, specialty of proceduralist, and experience with each respective procedure will potentially affect the rate of complications. ${ }^{1}$ Still, the literature has only a single report of spinal cord injury after cSCS. The present study reveals that there may be publication bias resulting in an underreporting of spinal cord injury after cSCS. The aforementioned shortcomings should be weighed against the number of cases, utilizing NIS data from the largest database reporting complications using cSCS in the US in a multicenter, nonselected hospital group fashion, beyond the confines of small case reports. Further studies to dissect the rates of complications with respect to the specific cSCS technique (e.g., percutaneous vs. paddle, anterograde vs. retrograde approach) are warranted.

\section{Conclusions}

This is the first study to robustly assess the perioperative complication and safety outcomes of cSCS. Prior to this study, there has been only one case report of perioperative spinal cord injury after cSCS. The present study reveals that spinal cord injury and neurological complications are underreported after cSCS, although the rates themselves are reassuringly low. Therefore, cSCS remains an option for the treatment of a variety of cervical pathologies in well-selected patients. Future multicenter prospective studies are needed to provide definitive analysis of efficacy, short-term complications, and, particularly, of long-term complication rates of cSCS.

\section{References}

1. Babu R, Hazzard MA, Huang KT, Ugiliweneza B, Patil CG, Boakye M, et al: Outcomes of percutaneous and paddle lead implantation for spinal cord stimulation: a comparative analysis of complications, reoperation rates, and health-care costs. Neuromodulation 16:418-427, 2013

2. Barolat G: Experience with 509 plate electrodes implanted epidurally from C1 to L1. Stereotact Funct Neurosurg 61:60-79, 1993

3. Buvanendran A, Young AC: Spinal epidural hematoma after spinal cord stimulator trial lead placement in a patient taking aspirin. Reg Anesth Pain Med 39:70-72, 2014

4. Calvillo O, Racz G, Didie J, Smith K: Neuroaugmentation in the treatment of complex regional pain syndrome of the upper extremity. Acta Orthop Belg 64:57-63, 1998

5. Dam-Hieu P, Magro E, Seizeur R, Simon A, Quinio B: Cervical cord compression due to delayed scarring around epidural electrodes used in spinal cord stimulation. J Neurosurg Spine 12:409-412, 2010

6. Deer T, Bowman R, Schocket SM, Kim C, Ranson M, Amirdelfan K, et al: The prospective evaluation of safety and success of a new method of introducing percutaneous paddle leads and complex arrays with an epidural access system. Neuromodulation 15:21-30, 2012

7. Deer TR, Skaribas IM, Haider N, Salmon J, Kim C, Nelson 
C, et al: Effectiveness of cervical spinal cord stimulation for the management of chronic pain. Neuromodulation 17:265271,2014

8. Elixhauser A, Steiner C, Harris DR, Coffey RM: Comorbidity measures for use with administrative data. Med Care 36:8-27, 1998

9. Falowski S, Ooi YC, Sabesan A, Sharan A: Spinal cord injury induced by a cervical spinal cord stimulator. Neuromodulation 14:34-37, 2011

10. Forouzanfar T, Kemler MA, Weber WE, Kessels AG, van Kleef M: Spinal cord stimulation in complex regional pain syndrome: cervical and lumbar devices are comparably effective. Br J Anaesth 92:348-353, 2004

11. Francaviglia N, Silvestro C, Maiello M, Bragazzi R, Bernucci $\mathrm{C}$ : Spinal cord stimulation for the treatment of progressive systemic sclerosis and Raynaud's syndrome. Br J Neurosurg 8:567-571, 1994

12. Franzini A, Ferroli P, Marras C, Broggi G: Huge epidural hematoma after surgery for spinal cord stimulation. Acta Neurochir (Wien) 147:565-567, 2005

13. Giberson CE, Barbosa J, Brooks ES, McGlothlen GL, Grigsby EJ, Kohut JJ, et al: Epidural hematomas after removal of percutaneous spinal cord stimulator trial leads: two case reports. Reg Anesth Pain Med 39:73-77, 2014

14. Hayek SM, Veizi IE, Stanton-Hicks M: Four-limb neurostimulation with neuroelectrodes placed in the lower cervical epidural space. Anesthesiology 110:681-684, 2009

15. Kloss BT, Sullivan AM, Rodriguez E: Epidural hematoma following spinal cord stimulator implant. Int J Emerg Med 3:483-484, 2010

16. Krainick JU, Thoden U, Riechert T: Pain reduction in amputees by long-term spinal cord stimulation. Long-term followup study over 5 years. J Neurosurg 52:346-350, 1980

17. Kumar K, Rizvi S: Cost-effectiveness of spinal cord stimulation therapy in management of chronic pain. Pain Med 14:1631-1649, 2013

18. Kumar K, Rizvi S, Bnurs SB: Spinal cord stimulation is effective in management of complex regional pain syndrome I: fact or fiction. Neurosurgery 69:566-580, 2011

19. Kumar K, Taylor RS, Jacques L, Eldabe S, Meglio M, Molet $\mathrm{J}$, et al: Spinal cord stimulation versus conventional medical management for neuropathic pain: a multicentre randomised controlled trial in patients with failed back surgery syndrome. Pain 132:179-188, 2007

20. Lad SP, Babu R, Bagley JH, Choi J, Bagley CA, Huh BK, et al: Utilization of spinal cord stimulation in patients with failed back surgery syndrome. Spine (Phila Pa 1976) 39:E719-E727, 2014

21. Lennarson PJ, Guillen FT: Spinal cord compression from a foreign body reaction to spinal cord stimulation: a previously unreported complication. Spine (Phila Pa 1976) 35:E1516E1519, 2010

22. Levy R, Henderson J, Slavin K, Simpson BA, Barolat G, Shipley J, et al: Incidence and avoidance of neurologic complications with paddle type spinal cord stimulation leads. Neuromodulation 14:412-422, 2011

23. McGovern RA, Sheehy JP, Zacharia BE, Chan AK, Ford B, McKhann GM II: Unchanged safety outcomes in deep brain stimulation surgery for Parkinson disease despite a decentralization of care. J Neurosurg 119:1546-1555, 2013

24. Meyer SC, Swartz K, Johnson JP: Quadriparesis and spinal cord stimulation: case report. Spine (Phila Pa 1976) 32:E565-E568, 2007

25. Moens M, De Smedt A, Brouns R, Spapen H, Droogmans $\mathrm{S}$, Duerinck J, et al: Retrograde $\mathrm{C} 0-\mathrm{C} 1$ insertion of cervical plate electrode for chronic intractable neck and arm pain. World Neurosurg 76:352-354, 268-269, 2011
26. North RB, Kidd D, Shipley J, Taylor RS: Spinal cord stimulation versus reoperation for failed back surgery syndrome: a cost effectiveness and cost utility analysis based on a randomized, controlled trial. Neurosurgery 61:361-369, 2007

27. North RB, Kidd DH, Farrokhi F, Piantadosi SA: Spinal cord stimulation versus repeated lumbosacral spine surgery for chronic pain: a randomized, controlled trial. Neurosurgery 56:98-107, 2005

28. Robaina FJ, Dominguez M, Díaz M, Rodriguez JL, de Vera JA: Spinal cord stimulation for relief of chronic pain in vasospastic disorders of the upper limbs. Neurosurgery 24:6367, 1989

29. Santiago FM, Santiago J, Prieto M, García-Sánchez MJ, Sánchez-Carríon JM, Martínez-Tellería A, et al: [Dorsal epidural hematoma after implantation of a dorsal nerve stimulator.] Rev Esp Anestesiol Reanim 52:440-441, 2005 (Span)

30. Scranton RA, Skaribas IM, Simpson RK Jr: Spinal stimulator peri-electrode masses: case report. J Neurosurg Spine 22:70-74, 2015

31. Simpson BA, Bassett G, Davies K, Herbert C, Pierri M: Cervical spinal cord stimulation for pain: a report on 41 patients. Neuromodulation 6:20-26, 2003

32. Smith CC, Lin JL, Shokat M, Dosanjh SS, Casthely D: A report of paraparesis following spinal cord stimulator trial, implantation and revision. Pain Physician 13:357-363, 2010

33. Vallejo R, Kramer J, Benyamin R: Neuromodulation of the cervical spinal cord in the treatment of chronic intractable neck and upper extremity pain: a case series and review of the literature. Pain Physician 10:305-311, 2007

34. Wada E, Kawai H: Late onset cervical myelopathy secondary to fibrous scar tissue formation around the spinal cord stimulation electrode. Spinal Cord 48:646-648, 2010

35. Whitworth LA, Feler CA: C1-C2 sublaminar insertion of paddle leads for the management of chronic painful conditions of the upper extremity. Neuromodulation 6:153-157, 2003

36. Wolter T, Kieselbach K: Cervical spinal cord stimulation: an analysis of 23 patients with long-term follow-up. Pain Physician 15:203-212, 2012

37. Wolter T, Winkelmüller M: Continuous versus intermittent spinal cord stimulation: an analysis of factors influencing clinical efficacy. Neuromodulation 15:13-20, 2012

\section{Disclosures}

The authors report no conflict of interest concerning the materials or methods used in this study or the findings specified in this paper.

\section{Author Contributions}

Conception and design: Chan, Jacques. Acquisition of data: Chan. Analysis and interpretation of data: Chan, Winkler. Drafting the article: Chan, Winkler. Critically revising the article: all authors. Reviewed submitted version of manuscript: all authors. Approved the final version of the manuscript on behalf of all authors: Chan. Statistical analysis: Chan. Administrative/technical/material support: Jacques. Study supervision: Jacques.

\section{Correspondence}

Andrew K. Chan, Department of Neurological Surgery, University of California, San Francisco, 505 Parnassus Ave., M779, San Francisco, CA 94143. email: andrew.chan@ucsf.edu. 